\title{
Narrativas de mujeres víctimas de violencia sexual durante el terrorismo de Estado en Uruguay: el valor de la denuncia como expresión política*
}

\author{
Narratives of women victims of sexual violence during state \\ terrorism in Uruguay: the value of denouncement as a political \\ expression
}

Narrativas de mulheres vítimas de violência sexual durante o terrorismo de estado no Uruguai: o valor da denúncia como expressão política

Ana Laura Cafaro Mango**

\section{RESUMEN}

La violencia sexual como crimen de lesa humanidad es de rePalabras clave: ciente data en el ámbito jurídico; pero también lo es desde una mirada de género en las ciencias sociales. El presente artículo se centra en las vivencias de un grupo de mujeres que durante la género, terrorismo de Estado, víctima, violencia sexual. actuación ilegítima y del terrorismo de Estado en el Uruguay entre el 13 de junio de 1968 y el 28 de febrero de 1985- sufrieron torturas y violencia sexual durante su detención, denunciando este hecho en el año 2011. Relatar y denunciar en el ámbito público y judicial, permitió a las mujeres moverse del lugar de víctimas hacia el de denunciantes, pasando de pasivas a la de ciudadanas. En el marco de un análisis interesado por los procesos políticos de construcción y reconocimiento de víctimas, el artículo también trabaja el valor de la denuncia donde lo colecti-

\footnotetext{
* El presente artículo se elaboró en el marco de la Convocatoria al Fortalecimiento de la Investigación y Producción Académica del Departamento de Trabajo Social, Facultad de Ciencias Sociales, Universidad de la República (Uruguay).

** Uruguaya. Magíster en Trabajo Social, Facultad de Ciencias Sociales, Universidad de la República. Docente e investigadora en el Departamento de Trabajo Social, Facultad de Ciencias Sociales, Universidad de la República. Montevideo, Uruguay. analaura. cafaro@cienciassociales.edu.uy
} 
vo aparece como recurso y sostén a partir de lo cual se va configurando la agencia de estas mujeres.

\begin{abstract}
Sexual violence as a crime against humanity is of recent date in the legal sphere, but it is also from a gender perspective in the social sciences. This article focuses on the 2011 report of a group of women who, during the illegitimate actions and state terrorism in Uruguay -between June 13, 1968, and February 28, 1985- suffered torture and sexual violence during their detention. Reporting and denouncing publicly and judicially allowed women to shift from victims to denouncers, from passive to citizens. From an analytical framework interested in the political processes of victims' construction and recognition, the article also works on the value of denunciation, where the collective is a resource and support force for these women
\end{abstract}

\section{RESUMO}

A violência sexual como crime de lesa-humanidade é recente no âmbito jurídico; e também a partir de uma perspectiva de gênero nas Ciências Sociais. O presente artigo está centrado nas vivências de um grupo de mulheres que, durante a ação ilegítima e do terrorismo de Estado no Uruguai -entre 13 de junho de 1968 e 28 de fevereiro de 1985-, sofreram torturas e violência sexual durante sua detenção, denunciando este fato em 2011. Relatar e denunciar nas esferas pública e judicial permitiu às mulheres se deslocarem da posição de vítimas para a de denunciantes, passando de uma atitude passiva a serem cidadãs. No contexto de uma análise interessada nos processos políticos de construção e reconhecimento de vítimas, o artigo também aborda o valor da denúncia no qual o coletivo aparece como recurso e apoio a partir do qual se configura a agência destas mulheres.
Keywords: gender, state terrorism, victim, sexual violence.

Palavras-chave: gênero, terrorismo de Estado, vítima, violência sexual. 


\section{Introducción}

Durante la actuación ilegítima del Estado (13 de junio de 1968 al 26 de junio de 1973), mediante las llamadas Medidas Prontas de Seguridad en el marco de la Doctrina de la Seguridad Nacional, y luego, desde el 27 de junio de 1973, día en que se da un golpe de Estado cívico-militar en el Uruguay hasta el restablecimiento de la democracia en febrero de 1985, se reconoce el quebrantamiento del Estado de Derecho y la responsabilidad del mismo en graves violaciones a los derechos humanos y crímenes de lesa humanidad. Estos comprendieron torturas, homicidios, desaparición forzada de personas, prisión prolongada, exilio político y destierro de la vida social. Estos actos fueron perpetuados por agentes del Estado y civiles bajo su amparo, dentro del territorio nacional pero también fuera del mismo, en el marco de la Operación Cóndor ${ }^{1}$.

El presente artículo se centra en las vivencias de un grupo de mujeres que durante ese período de actuación ilegítima y del terrorismo de Estado en el Uruguay, sufrieron - además de torturas - violencia sexual durante su detención, denunciando este hecho recién en 2011. La violencia sexual como crimen de lesa humanidad es de reciente data en el ámbito jurídico; pero también lo es desde una mirada de género en las ciencias sociales, sobre todo para el caso uruguayo que resulta aún poco explorado (González y Risso, 2012; Mangado y Robaina, 2012; Sapriza, 2010)2. A esto se suma la falta de consideración jurídica del problema en el marco de las leyes de reparación uruguayas, las que están lejos de incorporar la perspectiva de género.

Atravesado por preguntas relativas al género como vector analítico transversal, el artículo trabaja en los procesos políticos de reconocimiento de víctimas, así como de la experiencia y valor de la denuncia. Para esto, se ponen en diálogo los aportes de Gatti (2017) en cuanto a

\footnotetext{
1 La Operación Cóndor o Plan Cóndor refiere a la coordinación regional de acciones represivas y de colaboración de los regímenes dictatoriales en el Cono Sur que comprendían principalmente a Uruguay, Argentina, Brasil, Bolivia, Chile y Paraguay junto a los Estados Unidos.

2 Entre los trabajos que se pueden mencionar y que exploran esta vinculación, analizando las memorias de la represión política desde una perspectiva de género están Álvarez (2015; 2018a; 2018b); Aucía (2011); Bourke (2009); y Roque (2018), entre otros.
} 
la categoría víctima con las características que las propias mujeres van construyendo acerca de su experiencia vital.

En lo relativo a la estrategia metodológica, se realizaron entrevistas no estructuradas a algunas de las denunciantes y a una de las abogadas del equipo jurídico. En cuanto a las mujeres denunciantes, haber trabajado profesionalmente con tres de ellas ${ }^{3}$ facilitó el encuentro y, a la vez, que otras accedieran a ser entrevistadas. En un principio se quería realizar un grupo de discusión presencial que luego no fue posible, teniendo en cuenta que el trabajo de campo se llevó adelante cuando inició la emergencia sanitaria por COVID-19 y la cuarentena en Uruguay. Por tanto, se acordó con las entrevistadas realizar entrevistas individuales. Se llevaron a cabo siete entrevistas de manera virtual durante el mes de abril 2020. La técnica utilizada para llevar a cabo el trabajo de campo, fue la entrevista cualitativa no estructurada, donde se dispuso de un guion (Corbetta, 2007) en el cual se encontraban los temas que se pretendía tratar a lo largo de la entrevista que se organizó de acuerdo con algunos núcleos temáticos surgidos de los propios objetivos de la investigación. Esta técnica brindó a las entrevistadas la oportunidad de poner en palabras sus historias, reflexiones y sentires; en tanto que a la entrevistadora le permitió profundizar en temas emergentes. Para el estudio de las entrevistas se recurrió al análisis crítico del discurso (Van Dijk, 2009).

$\mathrm{Al}$ ser consultadas, las entrevistadas dieron su consentimiento ${ }^{4}$ para que las citas fueran realizadas con sus verdaderos nombres y no con

3 En 2019, como trabajadora social y docente fui invitada a integrarme a un grupo de ex-presas políticas - entre las cuales se encontraban tres de las entrevistadas- que comenzó a reunirse reivindicando la construcción del primer memorial que hiciera visible la lucha de las mujeres durante la actuación ilegítima y el terrorismo de Estado en Uruguay. En octubre de 2019, se colocó la piedra fundamental en un predio ubicado en los alrededores del Palacio Legislativo (Parlamento). Se ha dificultado conseguir los recursos económicos para la construcción del memorial, teniendo en cuenta que en marzo de 2020 asumió el gobierno el Partido Nacional y la coalición de derecha.

4 Las entrevistadas firmaron un consentimiento informado donde se indicaba en forma clara y breve los objetivos de la investigación, metodología, criterios para haber sido seleccionadas y la posibilidad del retiro voluntario en el momento que así lo deseara. Luego se les hizo llegar la transcripción de la entrevista, para que la pudieran leer e indicar si deseaban suprimir o corregir alguna parte antes de ser utilizada para su análisis. Se agradece muy especialmente los testimonios que brindaron para el presente trabajo Ana Amorós, Ivonne Klingler, Blanca Luz “Lucy” Menéndez, Brenda Sosa, Beatriz Weismann y Antonia Yáñez. 
seudónimos, así como tampoco con números ${ }^{5}$. Esto último, las ex-presas políticas lo vinculan en general con uno de los tantos tratos deshumanizantes que significó ser llamadas durante sus años de detención por un número y no por su nombre. La inclusión de los nombres de las entrevistadas y, en consecuencia, asumir con identidad propia lo que se dice resulta interesante y puede ser interpretado como acto político. Al respecto, Pollak y Heinrich (2006) señalan que tomar la palabra para relatar experiencias traumáticas y denigrantes puede ser, además, una tentativa de liberación.

A fin de estructurar el documento, en primer lugar, se expone la caracterización que realiza Gatti (2017) entre el viejo y nuevo espacio de las víctimas, en tanto tipos históricos e ideales. Luego, se desarrolla brevemente un apartado de las leyes con las que cuenta Uruguay hasta el momento en que reconoce a las víctimas de la actuación ilegítima y del terrorismo de Estado, a partir de la propia agencia de estas y no del impulso estatal una vez que se retorna a la democracia. En un tercer apartado se presentan los testimonios de las mujeres en cuanto a las experiencias vividas durante su detención y, en especial, los relatos del proceso que transitaron hasta realizar la denuncia por violencia sexual donde destaca especialmente la experiencia grupal que vivieron. Por último, se exponen algunas conclusiones y principales hallazgos.

\section{Víctimas de la actuación ilegítima y del terrorismo de Estado en Uruguay: entre el viejo y nuevo espacio}

Gatti (2017) invita a reflexionar acerca de la categoría de víctima haciendo un recorrido exhaustivo por la producción disponible en las ciencias sociales. Para ello, realiza una caracterización de tipos históricos e ideales, entre el viejo y el nuevo espacio de las víctimas. En el viejo espacio - que para el caso de España, por ejemplo, lo identifica con las víctimas de la acción de $\mathrm{ETA}^{6}$ - la víctima es un sujeto singular, extraordinario, situado por fuera de la sociedad, y se lo puede identificar

5 La única entrevistada que quiso permanecer en el anonimato se identifica como "Informante calificada equipo jurídico".

6 Señala Gatti (2017), "En esa narrativa, este grupo de víctimas - por lo demás, internamente muy heterogéneo, pero progresivamente imaginado como un bloque único y monolítico- fue posicionado en el lugar protegido de los sacrificados para el bien de otros (la ciudadanía). Con ellos se excluyó de la condición de víctima a otros muchos susceptibles de recibir ese marchamo" (p. 96). 
como mártir o héroe. Su presencia es sacrificial y heroica. En el nuevo espacio, en tanto, la víctima no se sitúa en los márgenes de la sociedad, sino que se ubica en el centro, convirtiéndose en un ciudadano-víctima. Sostiene Gatti (2017) que se puede hablar de la era de las víctimas cuando:

Se usa como herramienta para abordar la figura de la víctima como la representación más espectacular de las consecuencias indeseables de las políticas de identidad y de reconocimiento, en especial las que desde mediados del siglo XX ayudaron a situar en el espacio público reclamos asociados a la identidad étnica y de género. (p. 41)

La víctima del viejo espacio se define por el sufrimiento individual, es pasiva, se la asiste a partir de un derecho dañado, mientras que la del nuevo espacio se caracteriza por ser un sujeto común, un ciudadano participativo en lo público en tanto tiene agencia a partir de un derecho ganado (Gatti, 2017). La víctima del viejo espacio es un ser profundamente político e histórico, no así el sujeto de la era de las víctimas, que es universal y ahistórico. A partir de esta distinción se abre un campo extenso de expertos altamente tecnificado que incluye legislación, diagnósticos, protocolos, baremos, dispositivos "diseñados para incluir a las 'verdaderas víctimas'; y excluir a quienes no lo son" (Martínez, 2017, p. 62) 7 .

A partir del giro humanitario (Fassin 2010 en Gatti, 2017) después de la Segunda Guerra Mundial se genera un incremento significativo de los sujetos en posición de dolor donde "las situaciones asociadas a la categoría se amplían, el espacio de las víctimas se llena de demandas, de colectivos, de leyes" (Gatti e Irazuzta, 2017, p. 97).

$7 \quad$ Énfasis en el original. 
Tabla 1

Topologías de víctimas del viejo y el nuevo espacio

\begin{tabular}{|c|c|}
\hline $\begin{array}{l}\text { Viejo espacio de las víctimas } \\
\text { (tradicional) }\end{array}$ & $\begin{array}{c}\text { Nuevo espacio de las víctimas (era de } \\
\text { las víctimas) }\end{array}$ \\
\hline Sujeto extraordinario. & Sujeto común, ciudadano. \\
\hline $\begin{array}{l}\text { Víctima de raíz política, "víctimas } \\
\text { del terrorismo". }\end{array}$ & Red de afectados, identidad. \\
\hline Lugar especial. & Fluir transnacional. \\
\hline $\begin{array}{l}\text { Sujeto marcado por hecho } \\
\text { extraordinario: héroe, mártir, } \\
\text { honor, lucha, etc. Su presencia es } \\
\text { sacrificial y heroica. }\end{array}$ & $\begin{array}{l}\text { Pierde el carácter salvífico y purificador. } \\
\text { Ciudadano víctima. }\end{array}$ \\
\hline El dolor es individual. & $\begin{array}{l}\text { El dolor se seculariza y el cuidado se } \\
\text { banaliza; los sufrimientos son iguales. }\end{array}$ \\
\hline $\begin{array}{l}\text { Salvifica para el pacto político de } \\
\text { la sociedad. }\end{array}$ & Figura pierde carisma. \\
\hline Singularidad. & $\begin{array}{l}\text { Víctima se universaliza (ciudadano } \\
\text { afectado). } \\
\text { Situación de víctima es objeto de } \\
\text { atención rutinaria (tecnificación, } \\
\text { protocolos, agentes expertos, juzgados } \\
\text { especializados, formación del personal, } \\
\text { etc.). }\end{array}$ \\
\hline $\begin{array}{l}\text { Sensible a su historicidad; } \\
\text { profundamente político. }\end{array}$ & Concepción esencializada y ahistórica. \\
\hline Derecho dañado. & Derecho ganado. \\
\hline Pasivo-se le asiste. & Activo-tiene agencia. \\
\hline
\end{tabular}

Fuente: Elaboración propia sobre la base de Gatti (2017).

La topología que realiza Gatti (2017) acerca del concepto víctima permite un primer acercamiento para reconocer y analizar a las víctimas de la actuación ilegítima y del terrorismo de Estado en Uruguay como tales, en este caso, las mujeres que vivieron violencia sexual durante su detención en centros clandestinos y cárceles durante la dictadura. Por otra parte, esta topología ofrece la posibilidad de ir dialogando con otras concepciones y con los propios relatos de las mujeres entrevistadas.

Para empezar, quisiera ubicar el tema del reconocimiento/no reconocimiento que hace el Estado uruguayo de las víctimas del período en cuestión. En Uruguay, el 13 de octubre del 2006 se sanciona una primera ley, la 18.033, que otorga la Pensión Especial Reparatoria (en 
adelante PER), a personas que por causas políticas, ideológicas o gremiales se vieron obligadas a abandonar el país; estuvieron detenidas o fueron despedidas de la actividad privada por esos motivos, entre el 9 de febrero de 1973 y el 28 de febrero de 1985. Pero es la Ley 18.596, promulgada el 18 de septiembre del 2009 la que amplía su mirada y nomina - al decir de Segato (2003) - a las víctimas, más allá de que no lo hace desde una mirada de género. Reconoce en su Artículo 2 la responsabilidad del Estado uruguayo en la realización de prácticas sistemáticas de tortura, homicidios, aniquilación de personas, exilio político o destierro de la vida social, desaparición forzada y prisión sin intervención del Poder Judicial, "cometidas por parte de agentes del Estado o de quienes, sin serlo, hubiesen contado con la autorización, apoyo o aquiescencia de agentes del Estado" (Ley 18.596, Artículo 5). Define y distingue en sus Artículos 4 y 5 a las víctimas de la actuación ilegítima del Estado en el período comprendido entre el 13 de junio de 1968 hasta el 26 de junio de 1973; y del terrorismo de Estado, desde el 27 de junio de 1973 hasta el 28 de febrero de 1985, "que hayan sufrido la violación a su derecho a la vida, a su integridad psicofísica y a su libertad dentro y fuera del territorio nacional (...) por motivos políticos, ideológicos o gremiales" (Ley 18.596, Artículos 4 y 5).

Para ser reconocida/o como víctima, se creó una Comisión Espe$\mathrm{cial}^{8}$ que expide un documento que acredita su condición como tal, de acuerdo con una enumeración de 10 "causales": haber permanecido detenido/a por más de seis meses por motivos políticos, ideológicos o gremiales, sin haber sido procesado/a; haber fallecido durante el período de detención; haber sido declarados/as ausentes o desaparecidos/as; haber sufrido lesiones graves y gravísimas o haber fallecido por el accionar ilegítimo de agentes del Estado o civiles autorizados por los mismos; nacido/a durante la privación de libertad de su madre o detenido/a con madre o padre; niñas o niños que hayan permanecido desaparecidos/as; quienes se hayan visto obligados/as a abandonar el país por motivos políticos, ideológicos o gremiales o hayan sido reque-

8 En el Artículo 17 de la Ley 18.596 se menciona su integración: un delegado del Ministerio de Educación y Cultura (preside), uno del Ministerio de Economía y Finanzas, un delegado del Ministerio de Salud Pública y dos delegados designados por el Poder Ejecutivo a propuesta de las organizaciones representativas de las víctimas. 
ridos/as o hayan permanecido en la clandestinidad dentro del territorio nacional.

Una vez tipificadas - es decir, delimitada como víctima que incluye y a la vez excluye en base a qué daños son considerados-, se les reconoce el derecho a la reparación integral a través de medidas de restitución, indemnización, rehabilitación, satisfacción y garantías de no repetición (Artículo 3).

Según esta breve presentación, las víctimas de la acción ilegítima y del terrorismo de Estado podrían relacionarse - de acuerdo con la topología desarrollada por Gatti (2017) — con las víctimas tradicionales, del viejo espacio. Se trata de personas que fueron víctimas de raíz política en un momento específico de la historia del Uruguay a quienes, como tales, se quiere reconocer y, por ende, resarcir. Pero pueden también vinculares con las del nuevo espacio, sobre todo cuando se hace referencia al grupo de mujeres que hicieron la denuncia por violencia sexual.

¿Por qué estas últimas se encuentran entre el viejo y el nuevo espacio? Debido, entre otras cosas, a que obtuvieron ese derecho por su propia agencia, es decir, no fue el Estado el que impulsó su reconocimiento en tanto víctimas. Las entrevistadas señalan al respecto:

Yo milité en $\mathrm{Crysol}^{9}$ por esa ley [refiere a la Ley 18.033]. Hicimos incluso una carta pública, recolectamos firmas entre los ex-presos, muchas firmas. Nos entrevistamos con legisladores, con la Mesa Política del Frente Amplio ${ }^{10}$ para que lo declaren asunto político para que los legisladores del Frente la votaran. (Brenda Sosa)

Todo lo poco que se consiguió, se consiguió en base a la lucha. Yo me acuerdo de que para la primera ley prácticamente rodeamos el Palacio, estuvimos horas parados ahí, había compañeros que decían "yo me encadeno acá en la puerta del Palacio". Lo que se fue consiguiendo fue en base a tremendo esfuerzo, a tremenda lucha, y nunca fue lo que nosotros en realidad pedimos. (Ivonne Klingler)

$9 \quad$ Crysol es una asociación que nuclea a ex-presos y presas políticas en Uruguay.

10 El Frente Amplio fue fundado el 5 de febrero de 1971 y es una fuerza política uruguaya de izquierda y centroizquierda. Gobernó durante los años 2005 a marzo 2020. 
A su vez, no es una ley reparatoria universal en el sentido de que todo/a ex-preso/a político/a puede acceder a la PER. Por ejemplo, deja por fuera quienes, de acuerdo con la legislación laboral y de seguridad social, cobran un sueldo, una jubilación o pensión:

Mirá, en la [Ley] 18.033 estuve trabajando muchos meses en Crysol, ayudando en lo de la PER. Me la dieron y me la sacaron porque yo había sido funcionaria pública y la [Ley] 18.033 no los ampara. La [Ley] 18.596 es la que me da después la chance de cobrar la PER, previo a renunciar a mi jubilación. (Ana Amorós)

Bueno, yo en realidad, como quedé restituida en el Estado no pude entrar en esa reparación primera, por lo tanto, nunca tuve la PER. Y bueno, (...) yo me jubilé y mi jubilación es un par de miles de pesos más que la PER, con lo cual tampoco elegí esa opción, me quedé como estaba. (Antonia Yáñez)

Nosotros queríamos que fuera así porque era una reparación por haber estado presos, torturados y desaparecidos. Pero bueno, no salió porque (...) nosotros valoramos que seguir insistiendo en eso hacía que (...) había muchos compañeros que estaban muy mal económicamente y con la salud muy vulnerable, entonces aceptamos que fuera así. (Brenda Sosa).

La PER fue la posibilidad de que compañeros que comían en los tachos de basura, compañeros que estuvieron presos y que lucharon contra la dictadura y pusieron su vida frente a la picana (...) no tuvieran qué comer. (...) Porque yo no comí de los tachos de basura porque mi familia me ayudó, sino hubiera sido así. (Ivonne Klingler).

En la PER me complicaron la vida, porque fue bastante traumática mi experiencia con la PER. En realidad, a mí me la dieron y me llegó un telegrama de que no me correspondía porque yo me excedía del límite en mi sueldo. O sea, no era mi sueldo, pero lo que pasa es que ellos primero hicieron una interpretación errónea de la ley y después la corrigieron y quedamos los que habíamos cobrado y no correspondía. (...) Y a mí se me desbarrancó mi economía. (Blanca Luz “Lucy” Menéndez).

Las leyes de reparación no pueden restar el derecho de las personas a su gestión de jubilación, porque por eso estuvieron aportando toda la vida. Son dos conceptos diferentes: la reparación se da por 
un accionar ilegítimo del Estado, por una vulneración de derechos sobre la cual el Estado repara, eso es un concepto de derechos humanos. Otro concepto, de derecho laboral: el trabajo, la seguridad social. Son derechos económicos, sociales y culturales, se dan porque ella aportó, etcétera. (...) Son cosas que no se pueden mezclar ni confundir, una no puede reemplazar a la otra. (Informante calificada equipo jurídico).

Sobre la base de este reconocimiento/no reconocimiento como contradicción intrínseca del propio Estado uruguayo, se cuestiona también por parte de las mujeres entrevistadas el documento que se entregaba a quienes habían sido víctimas de la actuación ilegítima y del terrorismo de Estado:

Bueno, en realidad no te puedo decir que tenga un gran significado, pero está eso, es un documento que acredita que eso fue así. Es más, a mí siempre... te digo, yo lo he llegado a entender el término "víctima del terrorismo de Estado", me molesta, no me cae bien. (...) Yo siempre me consideré una revolucionaria, y en realidad admito y entiendo que la definición está bien, porque es lo que fuimos, pero el papel de "víctima" no me gusta. (Blanca Luz "Lucy" Menéndez).

Nos dejó muy mal a la mayoría de nosotros, porque no era eso lo que (...) el que te den ese "diploma" (...) porque eso de "víctima" muchas personas no lo aceptan, no se sienten "víctimas", se siente revictimizadas con algo así. (...) Sabés que a mí no me importó demasiado, ¿viste? Me molestaba, de repente, mucho más el que nos excluyesen de la Ley 18.033. Me molestó mucho más que nos obligasen a renunciar a la jubilación, pero no por los montos, sino por lo que significaba. (Ana Amorós).

No me acuerdo si yo la fui a buscar, la verdad que ya no me acuerdo, sé que eso existió y que... no va en desmedro de nada, pero no me acuerdo mucho cómo resolvimos. (Antonia Yáñez).

Respecto de cómo se tipificó a las víctimas en ambas leyes, una de las entrevistadas sostiene y a la vez realiza una reflexión interesante pasando de la singularidad a la universalidad del concepto (Gatti, 2017):

¿Quién es "víctima"? ¿Vladimir Roslik, que a las pocas horas de detenerlo ya estaba muerto? O sea, víctimas somos todos, de acuerdo con dónde te tocó, al momento que te tocó, y a una opción personal 
(...) Es imposible definir, terminar de definir la palabra "víctima". Todos los que lucharon, todos los que estuvieron ahí, todos los que dieron la mano, la señora que estaba regando su jardín y de repente yo venía caminando por la calle (...) iban a empezar a pedir documentos en esa calle, me ve la cara, me agarra de la mano y me mete para adentro de la casa; nunca supe cómo se llamaba, nunca la vi más, pero se jugó ella y toda su familia por meterme a mí para adentro, y de esos casos hubo cantidad. (Ivonne Klingler).

\section{Primeros testimonios y relatos}

Si bien "la víctima era lo que el ciudadano común no era" (Gatti, 2017, p. 39), cabe preguntarse acerca de su singularidad como tal, en tanto héroe, mártir o chivo expiatorio. Y aquí se encuentran diferencias si colocamos la mirada desde una perspectiva de género. Sapriza (2010), Forné (2011) y Ruíz (2017) entre otras, señalan que los primeros testimonios ${ }^{11}$ fueron fundamentalmente de varones que reforzaban la imagen de héroe y otras virtudes vinculadas con la masculinidad hegemónica ${ }^{12}$. Uno de los ejemplos de cómo las mujeres quedaron invisibilizadas en los relatos de la dictadura surge de la investigación realizada por Ruíz y Sanseviero (2012) sobre las rehenas ${ }^{13}$ que no han estado presentes en la memoria colectiva: "es un hecho consistente y duradero que no puede atribuirse a la ignorancia, porque siempre hubo información disponible sobre ellas, aunque fuera fragmentaria, a veces incompleta y siempre subsumida en la información sobre los hombres" (p. 142). A diferencia de los varones rehenes ${ }^{14}$ de quienes no existe duda de que vivieron como tales, el relato

11 En su mayoría eran testimonios de ex-presos políticos del Movimiento de Liberación Nacional-Tupamaros-, MLN. Este movimiento político y social de Uruguay surgió a mitades de 60 y tuvo una actuación como guerrilla urbana de izquierda. Al momento del golpe de Estado en 1973, el MLN ya había sido derrotado militarmente, y desarticulado. Desde 1989, se integra a la coalición de izquierda el Frente Amplio (Movimiento de Participación Popular, MPP) y accede al gobierno a través de José Mujica entre el 2010 y 2015. 12 Como excepción, podrían mencionarse los libros de Lilián Celiberti y Lucy Garrido (1989), Nélida Fontora (1989) y Graciela Jorge (1992), Mirta Macedo (1999, 2005, 2008). A estos, se le suman años después relatos testimoniales en el marco de procesos judiciales o denuncias internacionales (Mirta Macedo, 2014).

13 Grupo compuesto por mujeres con importante trayectoria militante pertenecientes al Movimiento de Liberación Nacional-Tupamaros-MLN: Alba Antúnez, María Elena Curbelo, Raquel Dupont, Yessie Macchi, Flavia Schilling, Gracia Dri, Cristina Cabrera, Stella Sánchez, Miriam Montero, Lía Maciel, Elisa Michelini.

14 Dirigentes del Movimiento de Liberación Nacional-Tupamaros-MLN: Raúl Sendic, Eleuterio Fernández Huidobro, Julio Marenales, Jorge Zabalza, José Mujica, Mauricio 
histórico no las incluye, y contrariamente a sus compañeros militantes, con el retorno de la democracia las mujeres rehenas no ocuparon cargos ni roles protagónicos en lo partidario y en el gobierno, limitándose su presencia a la militancia social o política o a su vida doméstica (Ruiz y Sanseviero, 2012). En relación con este tema, se lo coloca en forma espontánea como ejemplo por parte de las entrevistadas, ya que no se encontraba explícitamente entre las preguntas. Las mismas señalan:

El relato a tal punto es tan machista, que ni siquiera tuvieron en cuenta que hubo nueve rehenas mujeres. Cuando hablan de los rehenes siempre se nombran a ellos, pero antes de los rehenes hombres sacaron del Penal de Punta de Rieles a nueve mujeres, y las pusieron como rehenes. (Brenda Sosa).

Mirá, yo creo que en ese sentido hay un antes y un después en la conferencia de prensa que se hace cuando salen los rehenes del MLN. En ese momento yo creo que no solo se puso a los hombres en el centro, porque no había ni una sola mujer y había mujeres en la dirección del MLN, y ahí se desdibujaron una cantidad de cosas: no solo se dejó en un plano secundario a las mujeres, se dejó también en un plano secundario lo que fue la lucha del pueblo uruguayo contra la dictadura. (...) siempre digo que en este país poquísima gente sabe que además de los "rehenes", hubo "rehenas". (Blanca Luz "Lucy” Menéndez)

$\mathrm{Al}$ respecto, señala De Giorgi (2019) que:

Una vez que las mujeres comenzaron a reunirse para revisitar sus experiencias y escribir sus memorias, se tornó posible contar otro tipo de historia (...) Contestaron el relato heroico de la resistencia, dando cuenta de la experiencia carcelaria y su resistencia desde “historias mínimas", relatando el mundo de lo privado (de la cárcel) y el relato de una resistencia desde "lo femenino". (p. 7) ${ }^{15}$.

Por su parte, una de las entrevistadas relata:

Nosotras teníamos una política de resistencia en la cárcel que pasaba por no ser voluntarias de nada, porque había trabajos forzados y

Rosencof. Adolfo Wassen, Jorge Manera y Henry Engler.

15 Énfasis en el original. 
nosotras no hacíamos nada voluntariamente y, a veces, según fuera el trabajo que nos planteaban, nos negábamos (...) no hablábamos con ellos, no teníamos diálogo con ellos, no hacíamos las cosas voluntariamente sino a reglamento. (Brenda Sosa)

Nosotras relatamos más desde las tripas y los varones relatan, en principio, más con su cabeza, pensando de una forma mucho más racional, mucho más lógica. (...) Nosotras tenemos, y no me arrepiento en tenerla, esa lectura también desde el útero, pero no desde el útero como cuestión mía de futuro, sino como cuestión de la humanidad. (Ivonne Klingler).

Creo que las mujeres hemos contado más, me parece, ¿no? Que nos hemos exhibido más en la desnudez de lo que hemos vivido, me parece, ¿no? (...) Las que teníamos hijos, creo que las mujeres hemos hablado más de lo que significó esa separación de los hijos. (Beatriz Weismann).

Los primeros testimonios y relatos de las mujeres están fundamentalmente centrados en lo cotidiano, y tendrán que pasar varios años más para que se pueda colocar una mirada de género y más aún para hablar acerca de la violencia sexual sufrida durante el terrorismo de Estado, aunque había sido mencionada en el trabajo del Servicio Paz y Justicia, SERPAJ (1989):

Este tema específicamente no se hablaba porque, primero estábamos en zona del enemigo, no estábamos en nuestro territorio, ahí eran ellos y había que cuidarse; y además eran cosas que seguramente nos iban a movilizar de una forma que no era buena para aguantar. (Ivonne Klingler).

Lo que habíamos pasado no lo habíamos hablado ni siquiera con nuestros esposos, nuestras parejas; lo habíamos enterrado para poder seguir y construir nuestras vidas, ¿no? (Brenda Sosa).

Mirá, antes de eso [refiere a la denuncia e ir a declarar] el problema mayor que teníamos era cómo decírselo a nuestros hijos. Era más difícil que incluso ir a declarar. El hijo de Mirta Macedo fue el que abrió la puerta diciéndonos a todas "por favor vayan porque el que más, el que menos se imagina que eso pudo haber sucedido". (Ana Amorós). 
La violencia sexual no tiene nada de "heroico" como lo tenían los primeros relatos de los varones, sino que contenía para las mujeres un carácter estigmatizante, de culpa, pecaminoso, un sentimiento de traición, que por mucho tiempo no pudo ser relatado y fue silenciado en lo personal, pero también como imposición de un contexto silenciador y de impunidad (Cafaro, 2019). El tratamiento de la violencia sexual en el ámbito público fue, por tanto, un tema postergado ya que entre otras cosas pone en cuestión el orden sociocultural actual, no solo el del contexto del terrorismo de Estado. Retomando a Segato (2003), Sonderéguer (2012) señala que en el cuerpo de las mujeres se imprimió no solo el control físico - como acto domesticador - sino también moral sobre ellas, a la vez que ofició como "derrota de los otros" (p. 12). Agrega que en cuanto a los relatos de las personas sobrevivientes se construyen valoraciones y juicios morales negativos, donde se instala "el delito de la traición (...) en la circulación del cuerpo de las mujeres" (Sonderéguer, 2012, p. 12). Esto implica la presencia de valoraciones y visiones distintas para mujeres y varones: "mientras para los varones la traición tiene un signo de conversión ideológica o moral, la traición de las mujeres se vincula al tributo sexual, sea por la "entrega" o por sometimiento" (Sonderéguer, 2012, p. 11).

Yo te puedo asegurar que a mí me costó años y años sentirme flagelada, de sentirme loca, una prostituta, porque no había atinado a defenderme. Yo recuerdo que muchas veces, en ese local de la $\mathrm{OPR}^{16}$, muchas veces les dije a los compañeros "a mí me llegan a agarrar y los muerdo, les pego en los genitales”. Yo me imaginaba cualquier cosa y no hice nada. ¿Entendés Laura? (...) Esas cosas, cuando la gente te dice que algo habremos hecho, que deberíamos andar regalándonos a los milicos, esa fue otra de las formas que también... tenías que escuchar cualquier barbaridad. No se imaginan lo que fue, eso fue un calvario realmente, vivir con eso fue un calvario antes de hablarlo. (Ana Amorós).

La violencia sexual deja además un mensaje en dos direcciones (Segato, 2003): en el sentido vertical es moralizante para aquella mujer que salió del rol estereotipado; en el sentido horizontal, es un mensaje hacia la comunidad de pares en tanto los represores usurpan la propie-

16 Organización Popular Revolucionaria 33 Orientales, OPR-33. 
dad de los "subversivos", en este caso, el cuerpo de sus mujeres como objeto de conquista.

Me acuerdo de que expresamente iban algunos personajes conocidos de la tortura al penal y se acercaban y te miraban como diciendo: "mirá que estoy acá y lo que te pasó te puede volver a pasar cuando a mí se me antoje". Esta amenaza estaba permanente, las 24 horas. Entonces, con más razón, nosotras bajábamos cortina. (Ivonne Klingler).

En este sentido, se suma a los objetivos de quebrar a las mujeres para demostrar su dominación y castigarlas por no cumplir con el mandato de género, "el deseo de los represores de 'poseer' a las mujeres de sus enemigos (pensados en términos masculinos) y, si esto aún vivían, hacerles saber que esas mujeres 'ya no les pertenecían', que ese territorio también había sido ganado" (Álvarez, 2018, p. 65) ${ }^{17}$.

Cabe agregar lo que señala Jelin (2007) en cuanto a la rígida división sexual del trabajo antes y durante la dictadura, momento en que se recrudece la ideología patriarcal. Las mujeres, en tanto militantes, eran doblemente subversivas, ya que no cumplían con el mandato social de esposas-madres en el marco de la familia tradicional. La sociedad debía estar organizada sobre la base de esa única forma de nucleamiento estableciendo "un vínculo directo entre la estructura social y su raíz biológica, naturalizando los roles y valores familísticos". (Jelin, 2007, p. 41). El haberse "metido en cosas de hombres" (Benzano, 2014, p. 43) demonizaba la imagen sacralizada de las mujeres (Balcázar y Casas, 2011) y "los militares les recordaron y las castigaron por sus desvíos a los mandatos de género todos los días de su encierro" (De Giorgi, 2019, p. 6). Una de las entrevistadas señala en este sentido:

Las mujeres, para los milicos y para la sociedad, éramos doblemente macabras, por un lado, estábamos metidas con los sediciosos, cuando en realidad tendríamos que estar en nuestra casa cuidando hijos, lavando calzoncillos de nuestros maridos y cocinando, habíamos roto con todo eso. (Ana Amorós).

17 Énfasis en el original. 


\section{La denuncia como expresión política fáctica frente a la omisión del Estado}

De las mujeres entrevistadas, solo una de ellas había realizado una denuncia enseguida de salir de la cárcel estando exiliada; las demás, no lo habían hecho previamente. Así lo relatan las mujeres entrevistadas:

En realidad, yo asumí eso de ser denunciante apenas llegué a Suecia, como te decía, Yo tenía claro que había que denunciar, que no era una víctima llorosa de mi destino espantoso, sino que mi destino espantoso era espantoso para muchísima gente y que la única forma de que esto se parara o se lograra que no se repitiera (...) era denunciar, denunciar y denunciar (...) Me parecía que era mi principal obligación, sobre todo con los que seguían presos, ¿ ¿no? (...) Y ahora, después ya la obligación para las nuevas generaciones, ¿no? (Beatriz Weismann).

Fue sentirnos en el papel que teníamos que jugar nosotras, que nosotras teníamos el deber de transmitir lo que había sido nuestra experiencia para que ese fuera nuestro aporte a la garantía de no repetición. (Blanca Luz "Lucy” Menéndez).

Para mí fue un antes y un después de leer esa frase. Saramago dice "Somos la memoria que tenemos y la responsabilidad que asumimos, sin memoria no existimos y sin responsabilidad quizá no merezcamos existir". Yo creo que cuando uno se da cuenta, y fue un poco lo que conversábamos nosotras cuando decidimos dar este paso, de que no te podés morir sin haber dicho todo lo que te hicieron porque es un tema de responsabilidad, es un tema de nuestro aporte a esa lucha por el "Nunca más". (Blanca Luz "Lucy" Menéndez).

Claramente surge de estos testimonios lo expresado por Pollak y Heinrich (2006) en tanto son escasos "los testimonios producidos espontáneamente por fuera de solicitudes oficiales (de orden judicial, científico o histórico)" (p. 56) -como lo es el de Beatriz Weisman- por querer olvidar y adaptarse a la vida luego de la experiencia traumática; o para proteger a su familia del sufrimiento padecido. En otros casos, como en el de Blanca Luz "Lucy" Menéndez, el testimonio se brinda como prueba del horror vivido en aras de la no repetición. 
No resultó fácil el camino transitado hasta realizar la denuncia. Las mujeres cuentan que los primeros encuentros a la salida de la cárcel y durante muchos años, eran para festejar que estábamos bien, para contarnos una que estaba trabajando, la otra que estaba embarazada, la otra que se reencontró o no se reencontró con su pareja anterior. En una onda totalmente light, de divertirse de pasar (...) salimos, estamos vivas. (Ivonne Klingler).

Muchos años más tarde, cuando surge la posibilidad de realizar una visita a la cárcel de Punta de Rieles ${ }^{18}$, "empezamos a recordar cosas que habían pasado ahí, cosas terribles" (Ivonne Klingler) y fue a partir de ahí que se empezaron a reunir cada quince días cientos de mujeres en las instalaciones de la Asociación de Empleados Bancarios del Uruguay (AEBU), organizándose para: buscar apoyo psicosocial para poder realizar la denuncia sobre violencia sexual; buscar referentes jurídicos para armar un equipo de abogados/as para presentar la denuncia; integrarse al grupo de ex-presos/as para solicitar una Fiscalía Especializada en Delitos de Lesa Humanidad.

Pero iremos por partes: Las mujeres entrevistadas señalan que el proceso de conformación del grupo fue liderado por Mirta Macedo ${ }^{19} \mathrm{y}$ Beatriz Benzano:

La denuncia como tal de mujeres, en torno al tema de la violencia sexual, no estaba planteada en mi cabeza (...) Mirta, que es realmente la compañera que me convence, con la que conversamos, con la que tuvimos muchas cosas en común, entonces era más fácil comprenderla. (Antonia Yáñez).

Beatriz Benzano hizo un planteo que ella venía, justamente, creo que de Guatemala o de por allá, de una reunión por todo este tema, de la violencia contra las mujeres en particular, lo que implica el cuerpo de la mujer como botín de guerra. (Blanca Luz "Lucy" Menéndez).

18 La Cárcel de Punta de Rieles (Unidad No 6 de Punta de Rieles) está ubicada en Montevideo. A partir del año 1972, pasó a funcionar como un centro de reclusión de personas detenidas en el marco de la represión. En 1973 los hombres son trasladados al Penal de Libertad, y funciona hasta marzo del año 1985 como cárcel militar para más de 600 mujeres presas políticas.

19 Mirta Macedo muere el 24 de julio de 2012, pocos meses después de ir a declarar al Juzgado Penal por la causa que se viene presentando. 
Comenzaron a trabajar con la Cooperativa de Salud Mental y Derechos Humanos (CO.SA.ME.DD.HH.) para poder empezar a poner en palabras el terror sufrido. Resulta apropiado en este marco el concepto de comunidad de dolor acuñado por Veena Das (2008) que:

Refiere a la instancia en la que un sujeto dañado se funde con otros iguales (i.e., grupos de familiares, otras víctimas, grupos de duelo...) y da forma a un espacio expresivo singular, con el cuerpo y la palabra rasgadas como protagonistas. (...) Se crea un tipo especial de comunidad que permite la comunicación emocional y la solidaridad y que no hace de la superación del sufrimiento y de las 'narrativas en clave de re' (reparación, recuperación, etc.) su clave de bóveda. Son procesos sociales en los que sujetos cancelados por una experiencia de dolor y violencia inhabilitante hacen de ello una experiencia social habilitante. (Gatti, 2017, p. 66)

En paralelo a este proceso, buscan un equipo de abogados/as que pudiera asesorarlas, acompañarlas en la formulación y presentación de la denuncia y luego en las instancias judiciales. Pero, además, su agencia pasó por solicitar - junto con otras/os ex-presos/as políticos/ as- entre los años 2011 y 2012 la conformación de una Fiscalía Especializada en Crímenes de Lesa Humanidad que recién se puso en funcionamiento en febrero de 2018 y se encuentra, hasta la fecha, a cargo del fiscal Ricardo Perciballe. Así lo expresa una de las entrevistadas:

Nosotras nos planteamos muy tempranamente - en el 11 o 12- trabajar con la Comisión de Presupuesto de Hacienda, por ejemplo, fuimos recibidas finalmente para pedir justamente lo que era la Fiscalía Especializada. Hicimos una labor en ese sentido, porque claro, el problema era que no había manera de destrabar esta situación. (...) Así que bueno, había que hacer el camino también. (Antonia Yáñez).

El proceso hacia la denuncia no hubiese sido posible seguramente sin esa experiencia grupal que las habilitó para empezar a elaborar vivencias inenarrables. Más allá de que la presentación de la denuncia es vivenciada por las mujeres entrevistadas como "una obligación para las nuevas generaciones", como un "tema de responsabilidad", como un "acto de liberación", entre otros, cabe señalar que se vieron expuestas a revivir la violencia sexual, los sentimientos contradictorios, juicios y prejuicios propios y ajenos, el impacto en los vínculos afectivos 
por tener que relatar por primera vez a sus parejas, hijos/as, familiares, personas amigas la experiencia sufrida y enunciada y, a su vez, denunciada más de 30 años después.

A esto se le suma, la revictimización que expresan haber sufrido por parte de los operadores de justicia cuando tuvieron que ir a declarar. Desde tener que explicar, en forma insólita, el contexto histórico de la dictadura cívico-militar, pasando por preguntas que parecían poner en duda la veracidad del testimonio brindado o inclusive - más grave aún- una posible justificación; hasta la publicación de sus direcciones y teléfonos personales en los medios de prensa.

De pronto, encontrábamos un juez que se asombraba porque decía que era joven, que no lo había vivido. (Beatriz Weismann).

Ese juzgado realmente tenía un juez a la cabeza que no entendía nada, no entendía nada. No sé dónde había vivido antes, había sido acá pero no sé dónde había estado, porque no entendía nada y era muy violento con las preguntas. (Informante calificada equipo jurídico).

Costó muchas lágrimas, mucha impotencia de cómo poder transmitir las cosas frente a un juez que se paraba y como que no entendía nada de lo que se estaba diciendo, porque pedía detalles, entonces tenías que explicarle que estabas encapuchada, que estabas deshecha físicamente, que estabas lastimada, que no sabías nada, que no podías dar detalles de cómo había sido el hecho. Eso fue muy duro. (Ivonne Klingler).

¿Cuántas muertes tiene usted? Y yo le dije "Yo no tengo ninguna muerte, porque la organización a la que pertenecí no tuvo una sola muerte, no hubo ajusticiamientos", y me dijo "Sí, pero secuestros sí, y usted participó de uno". O sea, ¿me entendés, la cosa va en esto Laura: o sea que si tuviese muertos estaba bien que me violasen y todo lo demás, ¿entendés la mentalidad? Y con esos tipos nos tuvimos que ver. (Ana Amorós).

El mismo día que hicimos la denuncia, de noche, fuimos a tomar algo y nos enteramos de que en Montevideo Portal ${ }^{20}$ estaba el nom-

20 Medio de prensa digital. 
bre con las direcciones actuales y los teléfonos fijos de cada una. (...) Es importante porque fue espantoso, nos sentimos totalmente vapuleadas. Incluso a [nombra a una de las mujeres] la llamó la mujer de un milico ahí donde estábamos y le dijo que al marido le podía perdonar cualquier cosa, menos que se hubiese acostado con una ex-presa. (Ana Amorós).

Lo vivenciado por las mujeres atenta contra toda normativa internacional (Oficina del Alto Comisionado de las Naciones Unidas para los Derechos Humanos, Derechos Humanos de las Naciones Unidas, OHCHR, 2005) que apela a que el Estado vele - tanto en su derecho interno como en los procedimientos judiciales- por la no exposición a nuevos traumas durante la indagación. En especial, para los casos de violencia sexual, las Reglas de Procedimiento y Prueba de la Corte Penal Internacional (2002) establecen que no se debería exigir corroboración de las declaraciones de las víctimas para comprobar el crimen, a la vez que no puede inferirse en ninguna circunstancia su consentimiento. En este sentido, cabe señalar que es obligación del Estado formar a sus operadores en las llamadas "buenas prácticas" para la toma de testimonios de víctimas y testigos. Así lo señala una de las entrevistadas:

Reconozco que hay magistrados que han avanzado en capacitación —inclusive pagándose de su propio bolsillo- (...). Pero todavía falta mucho, la capacitación no puede ser una capacitación espasmódica, tiene que ser género-sensitiva permanente, que actualice a la gente, que les dé luz sobre lo que está vigente, sobre las obligaciones del Estado. (...) no estamos esperando que sean dadivosos, generosos, son obligaciones. Yo creo que mucho se desconoce a nivel del funcionariado público, hay mucho desconocimiento. Sobre todo acá, fíjate que en otros países de la región la tienen más clara. (Informante calificada equipo jurídico).

Volviendo a las "buenas prácticas" ${ }^{21}$, se puede mencionar a título de ejemplo una guía de trabajo elaborada por el Centro de Estudios Legales y Sociales de Argentina, CELS (2012) junto con víctimas sobrevivientes del terrorismo de Estado durante el proceso de justicia. En

21 No es objetivo de este trabajo analizar las llamadas "buenas prácticas" como un tipo de discurso más, que perfila el tratamiento de las personas que son consideradas víctimas. 
dicha guía se prevén las condiciones materiales en las que se deberían tomar las declaraciones teniendo en cuenta un trato humanitario, digno y en el marco de respeto de los derechos humanos que ya fueron violados en el pasado y debería evitarse la repetición en el presente. En esta guía, se señalan desde los modos de la convocatoria (forma en que es citada y nombrada la persona que atestigua); el apoyo psicosocial previo, durante y pasada la declaración; la forma en que se toma la declaración haciendo especial énfasis en el respeto por su intimidad, la escucha atenta y respetuosa; hasta temas aparentemente tan obvios como evitar el encuentro entre las personas acusadas y quienes atestiguan. Además, debería tenerse en cuenta que la evocación de los hechos ocurridos en el pasado se hace presente y esas vivencias retornan a través de "recuerdos intrusivos, sueños recurrentes, sensaciones de revivir la situación, que incluyen reacciones fisiológicas mensurables" (CELS, 2012, p. 9). Cabe señalar además que en la casi inevitable retraumatización de las víctimas durante la denuncia y declaración, sucede que resulta irrepresentable lo vivido "y ese resto no representable es lo que aparece entre las palabras, en las pausas, las interrupciones bruscas, las confusiones semánticas, los errores gramaticales y hasta en los silencios" (CELS, 2012, p. 10).

Si se considera entonces lo relatado por las mujeres entrevistadas, no se incorporaron estas medidas de cuidado a la hora de la declaración, lo cual las expuso a revivir los hechos traumáticos con posibles nuevos daños, además de ser nuevamente el Estado ejerciendo, de otra manera, situaciones de violencia institucional.

\section{A modo de reflexiones finales}

De acuerdo con lo expuesto, en este tema convergen movimientos vinculados con los derechos humanos; políticas de reconocimiento fundamentalmente en lo que refiere a la agenda de derechos hacia las mujeres; leyes a nivel nacional, regional e internacional, para que -en el caso aquí mencionado- las mujeres encontraran terreno fértil para comenzar a hablar y ser escuchadas, a la vez que denunciar la violencia sexual como una violencia específica ocurrida durante el terrorismo de Estado en el Uruguay.

En este sentido, y volviendo a la topología propuesta por Gatti (2017), podría afirmarse que habría algunas características que son 
propias de las víctimas del nuevo espacio, como las recién mencionadas. A su vez, el comenzar a relatar, denunciar en el ámbito público y judicial, permitió a las mujeres correrse del lugar de víctimas hacia el de denunciantes. Como señala Jelin (2001):

Cuando esto ocurre, la posición de víctima se retrae o esfuma (en términos jurídicos) abriendo camino para el surgimiento de un 'sujeto de derecho'. Su voz tiene entonces el valor testimonial, y puede ser escuchada y reconocida por los jueces y por la sociedad. (p. 236).

Es así como la víctima pierde su calidad de pasiva y pasa a la de ciudadana, devolviéndole de esta manera su capacidad de agencia, que en términos de Gatti (2017) es propia de la víctima del nuevo espacio.

Podría concluirse que las leyes 18.033 y 18.596 que nominan a las víctimas de la actuación ilegítima y del terrorismo de Estado en el Uruguay, no son suficientes en tanto en los hechos no existe una reparación integral. Más allá que el nominar implica un reconocimiento de lo ocurrido en ese período de la historia uruguaya, no parece haber tenido para las mujeres entrevistadas algo significativo, ya que por un lado la no integralidad en los hechos y, por otro, el contexto de impunidad en que sigue su denuncia, hace que la aspiración del Estado uruguayo de reconocer a las víctimas de ese período la vuelva a borrar con el puño.

Las mujeres entrevistadas hacen acuerdo en que es necesario nombrar en las leyes a quien ha sido víctima de determinados derechos vulnerados, en tanto acto de reconocimiento. Pero el no correrse de ese lugar, las estaría ubicando en un lugar pasivo y no activo, es decir, muy por el contrario de como ellas se definen y perciben.

El Estado uruguayo - frente al reconocimiento de las víctimas- no ha actuado de acuerdo con los principios y directrices básicas que se ha convenido en tratados internacionales y regionales, en el acceso a la justicia, en brindar las condiciones necesarias para que las personas no sean revictimizadas en el momento de su declaración, entre tantas otras cosas. No es necesario reiterar la violación de estos elementos a los que se vieron y siguen viendo expuestas las mujeres entrevistadas. Por tanto, no parecería que el Estado uruguayo actúe reparando un derecho dañado, según la topología de Gatti (2017), sino que son las mu- 
jeres las que, a través de su propia agencia, deben seguir luchando para "ganarse" el derecho de que la denuncia realizada tenga el andamiento jurídico que debe tener.

Un tema que resulta significativo para las mujeres, y será un aspecto para profundizar en futuras investigaciones, es el lugar que ocupa la acción colectiva en la búsqueda de reconocimiento y reparación de violencias, en este caso, de la violencia política y sexual sufrida. Las denunciantes señalan que no hubiesen podido dar ese paso sin la experiencia grupal, sin el sostén colectivo que les permitió dar el primer paso de poder poner en palabras entre ellas la violencia sexual vivenciada, para poder luego trasladarla a sus familias, amigos y amigas, y que todo eso se pudiera plasmar finalmente en una denuncia judicial. Es a partir de esa esfera colectiva - comunidad del dolor-que las mujeres que brindan sus testimonios en este artículo pasan a una experiencia social habilitante, en tanto activas denunciantes (Cafaro, 2018).

Finalmente cabe señalar que la violencia sexual como expresión del poder del patriarcado inscripta en los cuerpos de las mujeres, en tanto expresión domesticadora, moralizante y de conquista, sigue permaneciendo al decir de Pollak (2006) — salvo algunas excepciones como la del presente trabajo- en las memorias subterráneas frente a la memoria dominante de largo alcance.

\section{Referencias}

Álvarez, V. (2015). Género y violencia: Memorias de la represión sobre los cuerpos de las mujeres durante la última dictadura militar argentina. Revista Nomadias, (19), 63-83. https://nomadias. uchile.cl/index.php/NO/article/view/36763

Álvarez, V.(2018a). “Además me violaron". La violencia sexual en centros clandestinos de detención durante la última dictadura militar argentina (1976-1983). Iberoamericana Social, (3), 58-77. https://iberoamericasocial.com/ojs/index.php/IS/ article/view/339

Álvarez, V. (2018b). Denuncias y marcos de escucha para la violencia sexual en tribunales militares durante la última dictadura Argentina (1976-1983). Revista de Estudios de Género. La Ventana, 6(48), 423-458. http://www.scielo. 
org. $\mathrm{mx} /$ scielo.php?script=sci_abstract $\&$ pid $=\mathrm{S} 1405$ 94362018000200423\&lng=en\&nrm=iso\&tlng=es

Aucía, A. (2011). Género, violencia sexual y contextos represivos. En M. Vasallo (Ed.), Grietas del silencio. Una investigación sobre la violencia sexual en el marco del terrorismo de Estado (pp. 26-68). Comité de Latinoamérica y el Caribe para la Defensa de los derechos de la Mujer, Cladem.

Benzano, B. (2014). "Ponencia-Testimonio Beatriz Benzano" En: Grupo de denuncia de la Violencia Sexual sufrida durante el Terrorismo de Estado Vivencias del horror. Tortura sexual en las cárceles de Uruguay. Pp. 40-47. Montevideo: Irredentos Libros. Recuperado de: http://www.psicosocial.net/images/ IrredentosLibros/Vivencias-del-horror-Tortura-sexual-enlas-carceles-de-Uruguay.pdf

Balcázar, M. y Casas, L. (2011). "Ser mujer en un Centro Clandestino de Detención La deuda por una memoria completa." Trabajo presentado en el IV Seminario Internacional políticas de la memoria. Ampliación del campo de los derechos humanos. Memoria y perspectivas. Buenos Aires. Argentina. Recuperado de http://conti.derhuman.jus.gov.ar/2011/10/ mesa_9/balcazar_casas_mesa_9.pdf

Bourke, J. (2009). Los violadores: historia del estupor hasta nuestros días. Crítica.

Cafaro, A. L. (2018). Romper con el silencio: violencia sexual a presas políticas durante el terrorismo de Estado en Uruguay. En M. Alcántara, M. García, y F. Sánchez (Coords.), Filosofía $y$ pensamiento. Memoria del $56^{\circ}$ Congreso Internacional de Americanistas (pp. 117-125). Ediciones Universidad de Salamanca.

Cafaro, A. L. (2019). Las activas denunciantes: violencia sexual y terrorismo de Estado en Uruguay. Revista de Trabajo Social, 33(74), 36-49.

Celiberti, L. y Garrido, L. (1989). Mi habitación, mi celda. Cotidiano.

Centro de Estudios Legales y Sociales, CELS (2012). Guía de trabajo para la toma de testimonios a víctimas sobrevivientes de tortura. CELS.

Corbetta, P. (2007). Metodología y técnicas de investigación social. McGraw-Hill/Interamericana de España, SAU. 
Corte Penal Internacional (2002). Reglas de Procedimiento y Prueba. https://www.icc-cpi.int/resource-library/Documents/ RulesProcedureEvidenceSpa.pdf

Das, V. (2008). Sujetos del dolor, agente de dignidad. Universidad Nacional de Colombia.

De Giorgi, A. L. (2019). Mi habitación, mi celda. Experiencias y lecturas propias desde el feminismo en el Cono Sur en los 80. Revista de la Red de Intercátedras de Historia de América Latina Contemporánea, 6(11), 1-20. https://dialnet.unirioja.es/ descarga/articulo/7220816.pdf

Fontora, N. (1989). Más allá de la ignorancia. Publicaciones del Fogón.

Forné, A. (2011). Negociaciones genéricas en los relatos de Memoria para Armar. Stockholm Review of Latin American Studies, (7), 7186. https://www.lai.su.se/polopoly_fs/1.135175.1368788160!/ menu/standard/file/SRoLAS_07_2011.pdf

Gatti, G. (Ed.) (2017). Un mundo de víctimas. Anthropos.

Gatti, G. e Irazuzta, I. (2017). El ciudadano-víctima. Expansión, apertura y regulación de las leyes sobre vidas vulnerables. Athenea Digital, Revista de Pensamiento e Investigación Social, 17(3), 93-114. https://www.redalyc.org/pdf/537/53753454004.pdf

González, S. y Risso, M. (Comps.) (2012). Las Laurencias: violencia sexual y de género en el terrorismo de Estado uruguayo. Trilce.

Grupo de denuncia de la Violencia Sexual sufrida durante el Terrorismo de Estado (2014). Vivencias del horror. Tortura sexual en las cárceles de Uruguay. Irredentos Libros.

Jelin, E. (2007). Víctimas, familiares y ciudadanos/as: las luchas por la legitimidad de la palabra. Cuadernos Pagu, (29), 37-60. https://www.scielo.br/j/cpa/a/x8Pb4S35jKhkmbqrMXyBffd /?format=pdf\&lang=es

Jelin, E. (2001). Los trabajos de la Memoria. Siglo XXI Editores.

Jorge, G. (1992). La fuga de 13 palomas y 38 estrellas. Tae.

Ley 18.033 Seguridad Social (2006). Empleados privados. Destituidos. Beneficio de la Pensión Especial Reparatoria. https://www. impo.com.uy/bases/leyes/18033-2006

Ley 18.596 (2009). Reparación a las víctimas de la actuación ilegítima del Estado en el período comprendido entre el 13 de junio de 1968 y el 28 de febrero de 1985. https://www.impo.com.uy/ bases/leyes/18596-2009 
Martínez, M. (2017). Expertos en víctimas. En G. Gatti (Ed.), Un mundo de víctimas. Anthropos.

Mangado, L. y Robaina, M. (2012). La emergencia de un prolongado y silenciado dolor. En S. González Baica y M. Risso (Comps.), Las Laurencias: Violencia sexual y de género en el terrorismo de Estado uruguayo (pp. 25-38). Trilce.

Macedo, M. (2014). Cuando el humano deja de serlo. Reflexiones sobre algunos aspectos de la Tortura durante el Terrorismo de Estado en Uruguay. Asociación de Asistentes Sociales del Uruguay, Departamento de Trabajo Social (Facultad de Ciencias Sociales, UdelaR).

Macedo, M. (2008). De la prisión a la libertad. Reflexiones sobre los efectos sociales de la prisión. Ediciones Orbe libros.

Macedo, M. (2005). Atando los tiempos. Reflexiones sobre las estrategias de sobrevivencia en el Penal de Punta de Rieles 1976-1981. Ediciones Orbe libros.

Macedo, M. (2002). Tiempos de ida. Tiempos de vuelta. Ediciones Orbe libros.

Macedo, M. (1999). Un día, una noche... todos los días. diciones Orbe libros.

Oficina del Alto Comisionado de las Naciones Unidas para los Derechos Humanos (Derechos Humanos de las Naciones Unidas), OHCHR (2005). Principios y directrices básicos sobre el derecho de las víctimas de violaciones manifiestas de las normas internacionales de derechos humanos y de violaciones graves del derecho internacional humanitario a interponer recursos y obtener reparaciones. https://www.ohchr.org/sp/ professionalinterest/pages/remedyandreparation.aspx

Pollak, M. (2006). Memoria, olvido y silencio. En M. Pollak (Ed.), Memoria, olvido y silencio. La producción social de identidades frente a situaciones límite (pp. 17-32). Al Margen Editora.

Pollak, M. y Heinrich, N. (2006). El testimonio. En M. Pollak (Ed.), Memoria, olvido y silencio. La producción social de identidades frente a situaciones límite (pp. 53-112). Al Margen Editora.

Roque, S. (2018). Violência sexual e segurança internacional: despolitização, descontextualização e colonização de uma 
agenda. Revista Crítica de Ciências Sociais, (Special Issue), 165-188. https://doi.org/10.4000/rccs.7811

Ruiz, M. (2017). Las cartas que llegaron: resistencias "letradas" en el universo carcelario femenino del Uruguay dictatorial. Revue L'Ordinarie des Amériques, (222). https://doi.org/10.4000/ orda.3451

Ruiz, M. y Sanseviero, R. (2012). Las rehenas. Historia oculta de once presas de la dictadura. Fin de Siglo.

Sapriza, G. (2010). Memoria y memorias de mujeres en el relato de la dictadura (Uruguay 1973-1985). En J. M. Pedro y C. Scheibe Wolff (Comps.), Gênero, feminismos e ditaduras no Cone Sul (pp. 94-114). Mulheres.

Segato, R. (2003). Las estructuras elementales de la violencia. Contrato y estatus en la etiología de la violencia. Serie Antropológica 334. http://www.escuelamagistratura.gov.ar/images/ uploads/estructura_vg-rita_segato.pdf

Servicio Paz y Justicia, SERPAJ (1989). Uruguay nunca más: informe sobre la violación a los derechos humanos (1972-1985). https://sitiosdememoria.uy/sites/default/files/2020-01/ Serpaj\%20-\%201989\%20-\%20Uruguay\%20Nunca\%20Mas. pdf

Sonderéguer, M. (2012). Género y poder: violencias de género en contextos de represión política y conflictos armados. Universidad Nacional de Quilmes.

Van Dijk, T. (2009). Discurso y poder. Contribuciones a los estudios críticos del discurso. Editorial Gedisa. 